\title{
Prevalence and prevention of orthodontically induced dental resorption
}

\author{
Rehab Fuad Bawyan ${ }^{1 *}$, Ahmed Nayef Alsharif ${ }^{2}$, Wissam Hussain Alabdalaal ${ }^{3}$, \\ Abdulelah Saad Thakfan ${ }^{4}$, Sarah Taha Alesayi ${ }^{5}$, Ghadah Abdullah Shafei ${ }^{6}$, \\ Manal Mohammed Almarwani ${ }^{7}$, Basmah Mustafa Ageel ${ }^{8}$, Fatma Abdulqader Azouz ${ }^{5}$, \\ Asim Abdulaziz Alkhalifah ${ }^{2}$, Lamis Marwan Farghal', Ahmad Eissa Rawas ${ }^{10}$
}

\author{
${ }^{1}$ Department of Orthodontics, King Fahad General Hospital, Jeddah, Saudi Arabia \\ ${ }^{2}$ College of Dentistry, Qassim University, Qassim, Saudi Arabia \\ ${ }^{3}$ Dental Department, Qatif Central Hospital, Qatif, Saudi Arabia \\ ${ }^{4}$ College of Dentistry, King Khalid University, Abha, Saudi Arabia \\ ${ }^{5}$ General Dentist, Ministry of Health, Medina, Saudi Arabia \\ ${ }^{6}$ Faculty of Dentistry, King Abdulaziz University, Jeddah, Saudi Arabia \\ ${ }^{7}$ Primary Healthcare, Ministry of Health, Jeddah, Saudi Arabia \\ ${ }^{8}$ General Dentist, Ministry of Health, Tabuk, Saudi Arabia \\ ${ }^{9}$ College of Dentistry, Taibah University, Medina, Saudi Arabia \\ ${ }^{10}$ Department of Orthodontic, King Abdulaziz Hospital, Mecca, Saudi Arabia
}

Received: 17 November 2021

Accepted: 02 December 2021

*Correspondence:

Dr. Rehab Fuad Bawyan,

E-mail: R.bawyan2000@hotmail.com

Copyright: (C) the author(s), publisher and licensee Medip Academy. This is an open-access article distributed under the terms of the Creative Commons Attribution Non-Commercial License, which permits unrestricted non-commercial use, distribution, and reproduction in any medium, provided the original work is properly cited.

\section{ABSTRACT}

Since 1914, when Ottolengui first described it, dentists and patients have been tormented with root resorption, an unwanted but typical sequence of orthodontic mechanotherapeutics. It has been demonstrated that among other potentially hazardous chemicals, the orthodontic equipment employed has a considerable impact on root repair. The root repair process is highly linked to periodontal ligament necrosis damage. When intense orthodontic pressures are applied for an extended length of time, hyalinization of the underlying periodontal ligament can occur quickly. Protective leukocytes from periodontal ligament capillaries mix quickly with osteoclast progenitors to create cells with high-density genes capable of regenerating mineral tissue. External apical root repair begins when a protective layer of cementoblasts including the hyalinized periodontal ligament, dies, allowing odontoclasts to rebuild cement and teeth. Initially, a cemented protective layer is lost, exposing a green cement surface to odontoclastic assaults. On the other hand, the maxillary second premolar exhibited more excellent root rates in Asians than in Caucasians. The data were taken as evidence that specific races such as Asians were less likely than longer roots to be involved in root repair or were impacted by mutant morphology. In addition, radiographic examination of intermediate IOPAR therapy can detect at-risk teeth and suggest the necessity for appropriate rest to improve performance or anatomical structure. Treatment of afflicted individuals should be continued with caution and proper use of high-intensity light while avoiding movements linked with re-screening such as ingesting.

Keywords: Dental resorption, Orthodontics, Dental care, Dental health

\section{INTRODUCTION}

Since 1914, when Ottolengui first described it, dentists and patients have been tormented with root resorption, an unwanted but typical sequence of orthodontic mechanotherapeutics. ${ }^{1}$ Ketcham et al carefully researched the topic and wrote a seminal paper on it in 1927.,3 Since then, further study has been conducted and control and protection measures have been recommended. It has been 
demonstrated that among other potentially hazardous chemicals, the orthodontic equipment employed has a considerable impact on root repair. ${ }^{4}$ According to Hartsfiel et al roughly one out of every twenty orthodontic patients might be treated with at least a $5 \mathrm{~mm}$ root canal reduction. ${ }^{5}$ According to this data, root repairs are the second most prominent result of orthodontic treatment after white-spotted lesions on their tooth enamel. It has also been shown that root regeneration can occur during or after dental treatment, endangering the stability of treatment outcomes and dental health. A recent study has primarily focused on the link between cause and effect and potential preventative or therapy methods for this heinous occurrence. Furthermore, the study emphasized the genetic and molecular underpinnings of the disease and assisted nurses in determining who could be impacted. The purpose of this review was to offer the physicians and academics a grasp of the prevalence and prevention of the orthodontically induced dental resorption process.

\section{Methods}

This literature review was based on an extensive literature search in Medline, Cochrane and EMBASE databases which was performed on 15 November 2021 using the medical subject headings (MeSH) or a combination of all possible related terms, according to the database. To avoid missing potential studies, a further manual search for papers was done through Google Scholar while the reference lists of the initially included papers. Papers discussing prevalence and prevention of orthodontically induced dental resorption were screened for useful information. No limitations were posed on date, language, age of participants or publication type.

\section{DISCUSSION}

\section{Pathophysiology}

The root repair process was highly linked to periodontal ligament necrosis damage. When intense orthodontic pressures were applied for an extended length of time, hyalinization of the underlying periodontal ligament can occur quickly. Protective leukocytes from periodontal ligament capillaries mix quickly with osteoclast progenitors to create cells with high-density genes capable of regenerating mineral tissue. External apical root repair began when a protective layer of cementoblasts including the hyalinized periodontal ligament dies, allowing odontoclasts to rebuild cement and teeth. Initially, a cemented protective layer was lost, exposing a green cement surface to odontoclastic assaults. $^{6,7}$ Reduction was most often visible on radiographs in the apical root region because the third apical root was coated by cellular cement, which was dependent on active cells and vascular cells, the absence of which rendered the area prone to injury and associated cell damage. ${ }^{8}$ According to one study, blood veins filled
$47 \%$ of the periodontal ligament space at the apical region, compared to $4 \%$ at the cervix's end. ${ }^{9}$

In addition, the severity and hardness of the cementum modulus decreased from the cervix to the apical region, providing apical regions that were prone to regeneration. ${ }^{10}$ In addition, during movement, fullness of tooth movement (mid-rotation) was evident in the apical region of the roots. This, together with the variability in the shape of the periodontal fibers, can increase the trauma of one-third of the root system. ${ }^{5}$

\section{Arranging the dental resorption process}

Brezniak et al suggested the original categorization of root regeneration as a process technique. ${ }^{11}$ According to their definition, a regenerative event can only affect the outer surface of the tooth root while maintaining the capacity for complete regeneration or regeneration (cement or divine remodeling). Alternatively, root regeneration can reach dentine and produce a morphological change (tooth restoration) or it may progress and lead to complete repair of hard tissue, leading to a reduction in the root (circular root restoration). ${ }^{12}$

\section{Risk factors}

A review of the available literature revealed some risk factors that put the patient at risk of recurrent trauma when subjected to orthodontic equipment. These were either standard or local characteristics.

\section{Age, gender and race}

Although many studies showed a link between the patient's age at the start of treatment and the frequency of root canal, Sameshima et al found a rise in incidence in adults. ${ }^{13}$ Sinclair et al validated these findings in a nonhuman study corroborated them in human research. ${ }^{14,15} \mathrm{~A}$ reduction in periodontal vascularity and apathy and thick cement and its strong attachment to the third apical portion of adults were proposed reasons leading to the rise in root remodeling in adults. Although most research showed a minor interaction between genders and root canal reversal, Sinclair et al found a less substantial rise in male occurrence. ${ }^{13}$ Furthermore, there were conflicting claims that men and women were susceptible to the treatment, leaving experts perplexed. Sameshima et al were supported by recent research, whereas Geraldo et al were produced by gender inequality in the man experiencing root morphology with pipette-shaped roots among young males who reported a rising inclination for root repair. ${ }^{13,16}$ According to Kathryn et al theory, women have shorter root morphology than men of all ethnicities. ${ }^{17}$ Ethnic differences were considerable as demonstrated by studies indicating Asians were less likely to experience root recurrence than Caucasians and Hispanics. ${ }^{18}$ Kathryn et al investigated the length of pretreatment roots in four races. ${ }^{17}$ Caucasians and Hispanics 
were discovered to have deeper roots than Asians and Native Americans. On the other hand, the maxillary second premolar exhibited more excellent root rates in Asians than in Caucasians. The data were taken as evidence that specific races such as Asians were less likely than longer roots to be involved in root repair or were impacted by mutant morphology.

\section{Systematic pathologies}

The immune system and the root system have a close link as seen by the growing number of allergy patients. IgE levels were elevated in patients with asthma, atopy and allergies. ${ }^{19}$ Asthma, in especially, caused an imbalance between $\mathrm{T}$ helper one and $\mathrm{T}$ helper two cells, with the latter promoting lung congestion and inflammatory mediator production. ${ }^{20}$ The released cytokines attracted inflammatory cells in the lungs, producing an increase in histamine, prostaglandins and leukotrienes synthesis. These characteristic molecules entered the bloodstream and go to the periodontal ligament, where they interacted with target cells involved in tissue regeneration and tooth movement. ${ }^{21}$ Furthermore, excessive use of orthodontic force in asthmatic patients frequently resulted in tissue stress and necrosis and subsequent cell function, which led to the restoration of hard tissue. Aside from asthma, illnesses linked with poor bone turnover such as hypothyroidism, can cause greater stress on the roots of the teeth due to the orthodontic loads employed, resulting in root canals. ${ }^{22}$

\section{Hereditary links}

Numerous studies have sought to correlate root replacement with patient genetics and discovered that persons with homozygous IL-1 allele 1 were 5.6 times more likely to undergo root replacement than those who do not fit at all. These people have lower IL-1 secretion, which resulted in minor bone remodeling (regeneration) and more damage to the root structure. ${ }^{23,24}$ Another gene that appeared to be related to root restoration was TNFRSF11A gene, which received the bone healing protein RANK. Reduction of expression of any gene involved in bone remodeling can lead to dental root canal stress and can impair root repair. ${ }^{23,24}$

\section{Teeth physics and mechanics}

Most research has shown that medial incisors play an essential role in root retrieval. ${ }^{25-27}$ However, two studies the lateral incisors were the most affected, followed by molars and canines. ${ }^{28}$ The canine was the tooth with the highest recovery rate in the mandibular arch, followed by the lateral and central incisors. ${ }^{18}$ A study reported the anchoring bends placed on the mesial portion of the molars opening for the bite compressed the distal roots to bone sockets, resulting in substantial root retrieval on molar roots. ${ }^{29}$ Previous adversity and root restoration exhibited after orthodontic treatments is related with pretreatment root healing. ${ }^{30-32}$ The relationship between root length and resorption retrieval has also been proven to be beneficial. When compared to critical teeth, an increase in the number of teeth following endodontic therapy showed resistance to the regeneration process. ${ }^{33}$

\section{Orthodontic biomechanics and root resorption}

The critical condition of fixed devices has previously been examined compared to the treatment of tooth extracts. ${ }^{34}$ While Beck et al reported that there was no statistically significant difference in recovery rates between the light-wire mechanics and the edgewise techniques, a study reported that light-wire patients had a high incidence and increased root recurrence. ${ }^{29,35}$ It was observed that when the exercise was performed as part of the light-wire operating system, root canal regeneration increased fourfold. Alexander et al reported the presence of motion or circular motion during mechanotherapy was studied as a possible cause of recurrence. ${ }^{28}$ Root replacement had occurred as a result of excessive horizontal root transfer or torquing. ${ }^{36,37}$ Formalized paraphrase the most root replacements have been observed during the measurement of $3 \mathrm{~mm}$ torque motion. Almost all studies found a clear correlation between treatment duration and root replacement. ${ }^{36,37}$ A study investigated the influence of the type of energy utilized in the restorative pattern, whether continuous or interrupted, and discovered regions with the most negligible impact of apical blunting and low resorption when applied energy was impacted. ${ }^{38}$

\section{Dental root resorption at the middle of treatment}

Intra oral peri apical radiograph (IOPAR) continued to be the major investigative technique used to detect root restoration after treatment. To put the recovery procedure to the test, there were numerous catch programs and grading systems accessible. Modern digital imaging methods such as cone beam computed tomography (CBCT) with low radiation intensity and high precision, have proven to be indispensable. ${ }^{4}$ Durack et al compared IOAPR to CBCT for retrieval pits and determined that IOPAR had limitations and errors. ${ }^{39}$ The IOPAR test, according to Sherrard et al can lower root length by an average of $2.6 \mathrm{~mm}$, but the CBCT variance was only 0.3 $\mathrm{mm}$, making it a secondary testing approach. ${ }^{40}$ The main problems with using CBCT were the related quantities of radiation, the cost and the behavioral difficulties.

Panoramic radiographs used less radiation, needless patient and operating time and have higher patient cooperation, making them the most trustworthy approach, as evidenced by the difficulties of detecting the roots of direct morphology. ${ }^{22}$ Resorption in the middle incisors, it was not easy to identify. Figure 1 showed a comparison of the root canal process in the maxillary central incillator as detected by IOPAR and orthopantomography. To date, there were no reliable biomarkers identified for measurement on the side of the dental regeneration process. The need for chemical markers was enhanced by 
the acquisition of certain dental proteins in gingival crevicular fluid such as products from root replacement. ${ }^{41}$

\section{Healing and repair}

When orthodontic pressures were removed, active root regeneration ceases and the process of partial, functional or anatomic remodeling started. ${ }^{42,43}$ Partial repair occured when the new cementum did not cover the exposed dentine entirely, leaving an open gap. Functional healing occured when the exposed dentine was entirely covered with a thin layer of repair cementum, but the initial line was not re-established. The most common type of repair was anatomic correction, which involved restoring a portion of the root to its original line. In two studies, anatomic repair needed at least eight weeks of rest, whereas partial and functional corrective processes were visible during the first four weeks. ${ }^{42,43}$ A study in 1995, the percentage of the repair process was explicitly established as $25 \%$ during the first four weeks (partial discharge), $40 \%$ during the seven weeks (functional correction) and $12 \%$ beyond four weeks. ${ }^{44} \mathrm{~A}$ study found that an eight-week rest caused an anatomic correction in four examined teeth independent of the amount of force, compression or orthodontic damage done. ${ }^{43}$ It was determined that a four-week pause was required for the remedial procedure to be implemented.

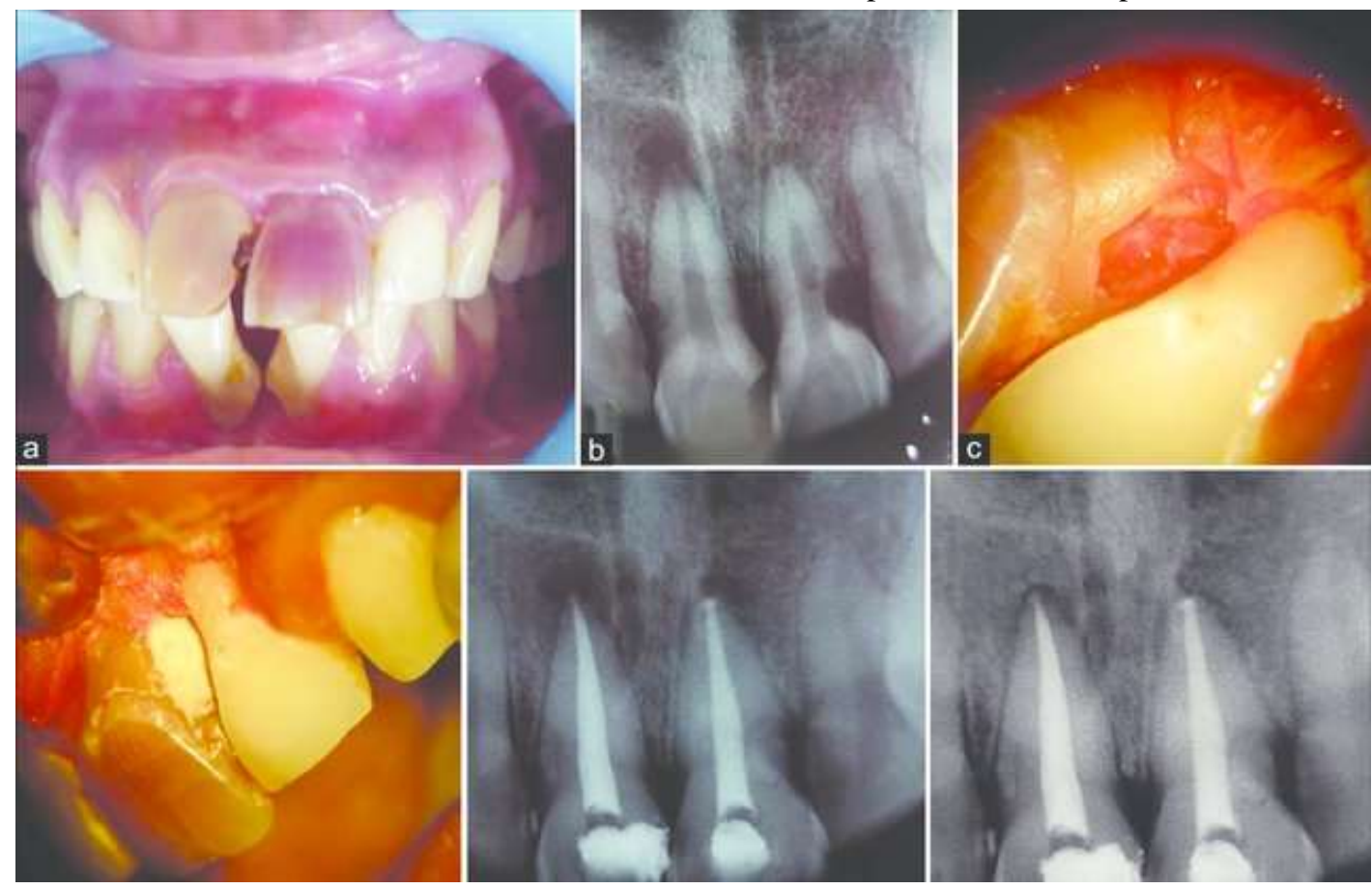

Figure 1: IOPAR imaging showing dental root resorption. ${ }^{46}$

The addition of cement or acellular cementum resulted in repairing root resorption particles, Vardimon et al used extension studies such as defective acellular correction and fast cellular healing to explain this process. ${ }^{45}$ The insertion of an acellular cellum through the bottom of the cavity thus defined the initial rise in repair tissue. Sharpey fiber was lightly attached to this stratum. Following that, embedded growth was seen using a cementum composite of extrinsic (Sharpey) and internal fibers. This was because of a distinct separating procedure. Acellular cementum was formed slowly and happened during the early phases of rest. Later, when healing was fast, cementocytes get stuck inside their animals because of complete mineral absorption. This theory was corroborated by two studies, who postulated conspicuous acellular cementum in dental restoration following shorter rest periods of two weeks compared to teeth with more extended rest periods (seven weeks). ${ }^{42,43}$

\section{CONCLUSION}

Orthodontic treatment is widely known to be associated with root reduction. A thorough medical history, preparatory feature testing, radiographic assessment of root morphology changes and cautious planning and orthodontic equipment, can all assist in reducing the incidence of root regeneration. Radiographic examination of intermediate IOPAR therapy can detect at-risk teeth and may suggest the necessity for appropriate rest to improve performance or anatomical structure. Treatment of afflicted individuals should be continued with caution and proper use of high-intensity light while avoiding movements linked with re-screening such as ingesting.

Funding: No funding sources Conflict of interest: None declared Ethical approval: Not required 


\section{REFERENCES}

1. Ottolengui R. The physiological and pathological resorption of tooth roots. Dent Item Interest. 1914;36:332.

2. Ketcham AH. A preliminary report of an investigation of apical root resorption of permanent teeth. Int J Orthodontia Oral Surg Radiograph. 1927;13(2):97-127.

3. Ketcham AH. A radiographic study of orthodontic tooth movement: a preliminary report. J Am Dent Assoc. 1927;14(9):1577-98.

4. Krishnan V. Critical issues concerning root resorption: a contemporary review. World J Orthod. 2005;6(1):30-40.

5. Abass SK, Hartsfield JK. Orthodontics and external apical root resorption. Seminar Orthodont. 2007.

6. Brudvik P, Rygh P. The initial phase of orthodontic root resorption incident to local compression of the periodontal ligament. Eur J Orthod. 1993;15(4):249-63.

7. Brudvik P, Rygh P. Root resorption beneath the main hyalinized zone. Eur J Orthod. 1994;16(4):249-63.

8. Brudvik P, Rygh P. Multi-nucleated cells remove the main hyalinized tissue and start resorption of adjacent root surfaces. Eur $\mathbf{J}$ Orthod. 1994;16(4):265-73.

9. Blaushild N, Michaeli Y, Steigman S. Histomorphometric study of the periodontal vasculature of the rat incisor. J Dent Res. 1992;71(12):1908-12.

10. Chutimanutskul W, Darendeliler MA, Shen G, Petocz P, Swain MV. Changes in the physical properties of human premolar cementum after application of 4 weeks of controlled orthodontic forces. Eur J Orthod. 2006;28(4):313-8.

11. Brezniak N, Wasserstein A. Orthodontically induced inflammatory root resorption. part II: the clinical aspects. Angle Orthod. 2002;72(2):180-4.

12. Malmgren O, Goldson L, Hill C, Orwin A, Petrini L, Lundberg M. Root resorption after orthodontic treatment of traumatized teeth. Am J Orthod. 1982;82(6):487-91.

13. Sameshima GT, Sinclair PM. Predicting and preventing root resorption: Part I. Diagnostic factors. Am $\mathrm{J}$ Orthod Dentofacial Orthop. 2001;119(5):505-10.

14. Ren Y, Maltha JC, Liem RS, Stokroos I, KuijpersJagtman AM. Age-dependent external root resorption during tooth movement in rats. Acta Odontol Scand. 2008;66(2):93-8.

15. Picanço GV, Freitas KMSD, Cançado RH, Valarelli FP, Picanço PRB, Feijão CP. Predisposing factors to severe external root resorption associated to orthodontic treatment. Dent Press J Orthodont. 2013;18(1):110-20.

16. CintraMartins-Ortiz JL, Braga SO. Analysis of predictors of root resorption in orthodontic treatment. J Dentist Oral Hygiene. 2011;3(3):46-52.
17. Edgcomb K. Prevalence of short dental roots in four ethnic groups in an orthodontic population. University of Illinois Chicago; 2011.

18. Sameshima GT, Sinclair PM. Predicting and preventing root resorption: part II. Treatment factors. Am J Orthod Dentofacial Orthop. 2001;119(5):511-5.

19. Davidovitch Z, Krishnan V. Adverse effects of orthodontics: a report of 2 cases. World J Orthodont. 2008;9(3).

20. Robinson DS, Hamid Q, Ying S, Tsicopoulos A, Barkans J, Bentley AM, et al. Predominant TH2-like bronchoalveolar T-lymphocyte population in atopic asthma. N Engl J Med. 1992;326(5):298-304.

21. Burstone CJ. The biophysics of bone remodeling during orthodontics (optimal force considerations). Biol Tooth Movement. 1989:321-33.

22. Abuabara A. Biomechanical aspects of external root resorption in orthodontic therapy. Medicina Oral Patología Oral Cirugía Bucal. 2007;12(8):610-3.

23. Al-Qawasmi RA, Hartsfield JK, Everett ET, Flury L, Liu L, Foroud TM, et al. Genetic predisposition to external apical root resorption. Am J Orthod Dentofacial Orthop. 2003;123(3):242-52.

24. Al-Qawasmi RA, Hartsfield JK, Hartsfield JK, Everett ET, Weaver MR, Foroud TM, et al. Root resorption associated with orthodontic force in IL1Beta knockout mouse. J Musculoskelet Neuronal Interact. 2004;4(4):383-5.

25. Janson GR, Canto GDL, Martins DR, Henriques JF, DeFreitas MR. A radiographic comparison of apical root resorption after orthodontic treatment with 3 different fixed appliance techniques. Am J Orthod Dentofacial Orthop. 2000;118(3):262-73.

26. L'Abee EM, Sanderink GC. Apical root resorption during Begg treatment. J Clin Orthod. 1985;19(1):60-1.

27. Remington DN, Joondeph DR, Artun J, Riedel RA, Chapko MK. Long-term evaluation of root resorption occurring during orthodontic treatment. Am J Orthod Dentofacial Orthop. 1989;96(1):43-6.

28. Alexander SA. Levels of root resorption associated with continuous arch and sectional arch mechanics. Am J Orthod Dentofacial Orthop. 1996;110(3):321-4.

29. Beck BW, Harris EF. Apical root resorption in orthodontically treated subjects: analysis of edgewise and light wire mechanics. Am J Orthod Dentofacial Orthop. 1994;105(4):350-61.

30. Mirabella AD, Artun J. Risk factors for apical root resorption of maxillary anterior teeth in adult orthodontic patients. Am J Orthod Dentofacial Orthop. 1995;108(1):48-55.

31. Newman WG. Possible etiologic factors in external root resorption. Am J Orthodont. 1975;67(5):522-39.

32. Brin I, Becker A, Zilberman Y. Resorbed lateral incisors adjacent to impacted canines have normal crown size. Am J Orthod Dentofacial Orthop. 1993;104(1):60-6. 
33. Spurrier SW, Hall SH, Joondeph DR, Shapiro PA, Riedel RA. A comparison of apical root resorption during orthodontic treatment in endodontically treated and vital teeth. Am J Orthod Dentofacial Orthop. 1990;97(2):130-4.

34. Linge BO, Linge L. Apical root resorption in upper anterior teeth. Eur J Orthod. 1983;5(3):173-83.

35. McNab S, Battistutta D, Taverne A, Symons AL. External apical root resorption following orthodontic treatment. Angle Orthodont. 2000;70(3):227-32.

36. Baumrind S, Korn EL, Boyd RL. Apical root resorption in orthodontically treated adults. Am J Orthod Dentofacial Orthop. 1996;110(3):311-20.

37. Parker RJ, Harris EF. Directions of orthodontic tooth movements associated with external apical root resorption of the maxillary central incisor. Am J Orthod Dentofacial Orthop. 1998;114(6):677-83.

38. Acar A, Canyürek U, Kocaaga M, Erverdi N. Continuous vs. discontinuous force application and root resorption. Angle Orthod. 1999;69(2):159-63.

39. Durack C, Patel S, Davies J, Wilson R, Mannocci F. Diagnostic accuracy of small volume cone beam computed tomography and intraoral periapical radiography for the detection of simulated external inflammatory root resorption. Int Endod J. 2011;44(2):136-47.

40. Sherrard JF, Rossouw PE, Benson BW, Carrillo R, Buschang PH. Accuracy and reliability of tooth and root lengths measured on cone-beam computed tomographs. Am J Orthod Dentofacial Orthop. 2010;137(4):100-8.
41. Mah J, Prasad N. Dentine phosphoproteins in gingival crevicular fluid during root resorption. Eur J Orthod. 2004;26(1):25-30.

42. Owman-Moll P, Kurol J. The early reparative process of orthodontically induced root resorption in adolescents--location and type of tissue. Eur J Orthod. 1998;20(6):727-32.

43. Cheng LL, Türk T, Elekdağ-Türk S, Jones AS, Yu Y, Darendeliler MA. Repair of root resorption 4 and 8 weeks after application of continuous light and heavy forces on premolars for 4 weeks: a histology study. Am J Orthod Dentofacial Orthop. 2010;138(6):727-34.

44. Owman-Moll P, Kurol J, Lundgren D. Repair of orthodontically induced root resorption in adolescents. Angle Orthod. 1995;65(6):403-8.

45. Vardimon AD, Graber TM, Pitaru S. Repair process of external root resorption subsequent to palatal expansion treatment. Am J Orthod Dentofacial Orthop. 1993;103(2):120-30.

46. Baranwal AK. Management of external invasive cervical resorption of tooth with Biodentine: a case report. J Conserv Dent. 2016;19(3):296-9.

Cite this article as: Bawyan RF, Alsharif AN, Alabdalaal WH, Thakfan AS, Alesayi ST, Shafei GA, et al. Prevalence and prevention of orthodontically induced dental resorption. Int J Community Med Public Health 2022;9:502-7. 